\title{
Incidence and short-term consequences of delirium in critically ill patients: A prospective observational cohort study ${ }^{\text {th }}$
}

\author{
Mark van den Boogaard ${ }^{\mathrm{a}, *}$, Lisette Schoonhoven ${ }^{\mathrm{b}}$, Johannes G. van der Hoeven ${ }^{\mathrm{a}, \mathrm{c}}$, \\ Theo van Achterberg ${ }^{\mathrm{b}}$, Peter Pickkers ${ }^{\mathrm{a}, \mathrm{c}}$ \\ a Department of Intensive Care Medicine, Radboud University Nijmegen Medical Centre, The Netherlands \\ ${ }^{\mathrm{b}}$ Scientific Institute for Quality of Healthcare, Radboud University Nijmegen Medical Centre, The Netherlands \\ ${ }^{\mathrm{c}}$ Nijmegen Institute for Infection, Inflammation and Immunity (N4i), Radboud University Nijmegen Medical Centre, The Netherlands
}

\section{A R T I C L E I N F O}

\section{Article history:}

Received 28 May 2011

Received in revised form 17 November 2011

Accepted 28 November 2011

\section{Keywords:}

Delirium

Incidence

Short-term outcome

Critical care

Intensive care

\begin{abstract}
A B S T R A C T
Background: Delirium is a serious and frequent psycho-organic disorder in critically ill patients. Reported incidence rates vary to a large extent and there is a paucity of data concerning delirium incidence rates for the different subgroups of intensive care unit (ICU) patients and their short-term health consequences.

Objectives: To determine the overall incidence and duration of delirium, per delirium subtype and per ICU admission diagnosis. Furthermore, we determined the short-term consequences of delirium.

Design: Prospective observational study.

Participants and setting: All adult consecutive patients admitted in one year to the ICU of a university medical centre.

Methods: Delirium was assessed using the Confusion Assessment Method-ICU three times a day. Delirium was divided in three subtypes: hyperactive, hypoactive and mixed subtype. As measures for short-term consequences we registered duration of mechanical ventilation, re-intubations, incidence of unplanned removal of tubes, length of (ICU) stay and in-hospital mortality.

Results: 1613 patients were included of which 411 (26\%) developed delirium. The incidence rate in the neurosurgical (10\%) and cardiac surgery group (12\%) was the lowest, incidence was intermediate in medical patients (40\%), while patients with a neurological diagnosis had the highest incidence (64\%). The mixed subtype occurred the most (53\%), while the hyperactive subtype the least (10\%). The median delirium duration was two days [IQR 1-7], but significantly longer $(P<0.0001)$ for the mixed subtype. More delirious patients were mechanically ventilated and for a longer period of time, were more likely to remove their tube and catheters, stayed in the ICU and hospital for a longer time, and had a six times higher chance of dying compared to non-delirium ICU patients, even after adjusting for their severity of illness score. Delirium was associated with an extended duration of mechanical ventilation, length of stay in the ICU and in-hospital, as well as with in-hospital mortality.

Conclusions: The delirium incidence in a mixed ICU population is high and differs importantly between ICU admission diagnoses and the subtypes of delirium. Patients with
\end{abstract}

\footnotetext{
iv This paper was submitted as an entry for the European Academy of Nursing Science's Rosemary Crow award, sponsored by the International Journal of Nursing Studies. The award is open to current doctoral students or recent graduates of the academy's programme.

* Corresponding author at: Radboud University Nijmegen Medical Centre, Department of Intensive Care, P.O. Box 9101, Internal Post 685, 6500HB Nijmegen, The Netherlands.

E-mail addresses: m.vandenboogaard@ic.umcn.nl (M. van den Boogaard), l.schoonhoven@iq.umcn.nl (L. Schoonhoven), j.vanderHoeven@ic.umcn.nl (J.G. van der Hoeven), t.vanachterberg@iq.umcn.nl (T. van Achterberg), p.pickkers@ic.umcn.nl (P. Pickkers).
} 
delirium had a significantly higher incidence of short-term health problems, independent from their severity of illness and this was most pronounced in the mixed subtype of delirium. Delirium is significantly associated with worse short-term outcome.

(c) 2011 Elsevier Ltd. All rights reserved.

\section{What is already known about this topic}

- Delirium occurs frequently in critically ill patients and is categorised in a hyperactive, hypoactive and mixed subtype and associated with serious short-term health problems. The mixed subtype occurs most frequently, but incidences per ICU diagnosis and the extent of shortterm health problems are unknown.

What this paper adds

- Delirium incidence rates varies between the different ICU admission categories with the highest incidence rate in neurological patients and the lowest in cardiac surgery patients.

- Cardiac surgery patients most likely suffer from the hyperactive delirium subtype, which is less common in other admission categories.

- Patients with mixed delirium subtype suffered the most from short-term consequences.

- Delirium in ICU patients is significantly associated with extended duration of mechanical ventilation, length of stay in the ICU and in-hospital, and with in-hospital mortality.

\section{Introduction}

Patients in the intensive care unit (ICU) are severely ill and need support of one or more organ functions. In the last decade, there is an increasing interest in brain dysfunctions such as delirium. Delirium is a syndrome defined as an acute onset of disturbances in consciousness and changes in cognition with a fluctuating course (American Psychiatric Association, 1994). Three subtypes of delirium can be distinguished (Peterson et al., 2006). A hyperactive delirium subtype with symptoms of hyperalertness, agitation, delusions and hallucinations, a hypoactive subtype in which the patient is hypoalert, lethargic, motorically slow and has inappropriate speech and the alternating or mixed subtype. The latter subtype of delirium is characterised by alternating symptoms of hyperactive and hypoactive delirium. The Richmond Agitation Sedation Scale (RASS) ranging from +4 (heavily agitated) to -5 (coma) in combination with the delirium diagnose (Ely et al., 2003) is used to distinguish between the three delirium subtypes (Pandharipande et al., 2007; Peterson et al., 2006). Only positive RASS scores indicates a hyperactive delirium subtype. Delirious patients who only have RASS scores between 0 and -3 are defined as hypoactive delirious patients. Patients with fluctuating RASS scores, between +4 and -3 in combination with a positive delirium screening, are defined as mixed or alternating subtype. These delirium subtypes have different implications for nurses since the hyperactive subtype is easy to recognize but causes more nursing problems and inconvenience. While patients with the hypoactive subtype are, due to their lethargic state, easy to nurse but therefore also easily missed or misdiagnosed as sedation of depression (American Psychiatric Association, 1994). Meagher and Trzepacz (Meagher et al., 2000; Meagher and Trzepacz, 2000) suggest that the different delirium subtypes in hospitalized patients represent a difference in severity of delirium. They argue that, since the duration of a hyperactive delirium is shorter than the duration of the mixed subtypes, and the length of stay in hospital is also shorter, the hyperactive subtype is less severe than the other subtypes. Whether this difference in severity of delirium is also true for ICU patients is not known.

Delirium in ICU patients is associated with short-term health consequences such as prolonged duration of mechanical ventilation and length of stay and higher mortality rates (Dubois et al., 2001; Ely et al., 2001a; Ouimet et al., 2007). The duration of delirium is associated with prolonged cognitive failure (Girard et al., 2010) and each additional day with delirium is associated with a $10 \%$ increase in mortality (Pisani et al., 2009).

The delirium incidence in ICU patients ranges from 11 to $89 \%$ (Aldemir et al., 2001; Dubois et al., 2001; Ely et al., 2007; McNicoll et al., 2003; Ouimet et al., 2007). Despite the generally high delirium incidence rate accompanied and the serious health consequences there is lack of evidence for prevention of delirium ICU patients. Preventive measures consisting of a multicomponent intervention strategy (Inouye et al., 1999) and prophylactic haloperidol (Kalisvaart et al., 2005) showed positive effects in older hospitalized patients with a high risk for delirium. The effects of these preventive measures are not determined yet in ICU patients.

The high incidence rate in critically ill patients is associated with the frequent occurrence of important risk factors for delirium (Van Rompaey et al., 2008) in ICU patients. The wide range of delirium incidence rates is likely related to case mix differences over studies. It is likely that overall delirium incidence rates and rates per subtype of delirium differ between (elective) surgical and medical patient groups. As these patient groups differ, e.g. regarding their pathophysiological disease processes, severity of illness, and chance of dying (Knaus et al., 1985) we expect them to also differ in their chances of developing delirium, or chances of developing a specific subtype.

Although the classification of the delirium subtypes according to Peterson et al. (2006) is commonly used in the ICU, little is known about incidence rates of the subtypes per ICU diagnosis group and its effects on delirium duration and short-term consequences.

The aim of this study is threefold. First, to determine the delirium incidence rate overall, per subtype of delirium and per ICU diagnosis group. Second, to determine the 
delirium duration overall, per subtype and per ICU diagnosis group. Third, to determine differences in short-term consequences between delirious and nondelirious patients, and for the delirium subtypes and to determine the contribution of delirium to these short-term consequences.

\section{Methods}

The study was approved by the local Medical Ethical Committee (study number 2007/283), which waived the need for informed consent since no interventions were carried out. The study was registered in the Clinical trial register as NCT00604773.

\subsection{Study design, sample and setting}

We performed a prospective cohort study between February 2008 and February 2009 in which all consecutive ICU patients were included and systematically screened for delirium. The study was carried out in the Radboud University Nijmegen Medical Centre, The Netherlands. This is a 960-bed university hospital that includes a level-3 ICU (highest level) with 33 ICU-beds for adults. Annually, approximately 2000-2500 (surgical, cardiac surgery, neurosurgical, neurological, medical, and trauma) ICU patients are admitted.

\subsection{Delirium screening}

Ideally, delirium is diagnosed by a psychiatrist, geriatrician or neurologist, as this is considered the 'gold standard'. However, this is not feasible in the ICU. Therefore, several delirium assessment tools have been developed for daily use by ICU nurses. Worldwide, the validated confusion assessment method (CAM)-ICU (Ely et al., 2001b,c) is mostly used and has the highest sensitivity and specificity (van den Boogaard et al., 2010). In the present study, all adult ICU patients were screened at least three times a day by trained ICU nurses (van den Boogaard et al., 2009) using the validated Dutch version of the CAM-ICU (Vreeswijk et al., 2009). Screening was performed more often if required, for example following sudden changes in behaviour, attention or consciousness. The implementation of the CAM-ICU in our daily practice is described elsewhere (van den Boogaard et al., 2009). In brief, a tailored implementation strategy was used and ICU nurses were trained at the bedside by a delirium expert nurse after they first followed $1 \mathrm{~h}$ of group training concerning the use of the CAM-ICU. Furthermore, we used 'delirium key-nurses' for further instructions and support of the nurses. Importantly, the use of the CAM-ICU was fully supported by the medical and nursing staff. Based on the CAM-ICU result, patients were treated with haloperidol or not.

Patients were excluded for this study if: they were admitted to the ICU for less than one day; had a sustained Richmond agitation sedation score (RASS) of $-4 /-5$ during complete ICU admission; had serious auditory or visual disorders; were unable to understand Dutch; were mentally disabled; suffered from a serious receptive aphasia or if the compliance rate of the delirium screening was $<80 \%$ during a patient's stay in the ICU.

Patients who were discharged from the ICU with delirium were followed on the ward until the end of the delirium episode. On the wards, patients were screened for delirium three times a day with the delirium observation scale. This scale is developed and validated by Schuurmans et al. (2003) and is commonly used in daily practice (Pretto et al., 2009).

\subsection{Outcome measures}

Patients were diagnosed with delirium when they had at least one positive CAM-ICU screening during their complete ICU stay. Delirium was divided in three subtypes (Fig. 1). The duration of delirium was measured per $8 \mathrm{~h}$ shift, expressed in days and defined as time from first positive CAM-ICU until the beginning of three consecutive days of negative delirium screenings (ICU patients: negative CAM-ICU, ward patients delirium observation scale score $<3$ ). Patients who died or were discharged from the hospital while delirious were discarded for the delirium duration calculations.

The delirium incidence rate was calculated in all included ICU patients. In addition, we calculated the delirium incidence rate in patients admitted for two days or longer separately.

We defined short-term consequences of delirium as: days on the mechanical ventilator, need for re-intubation, incidence rate of unplanned removal of tubes or catheters by the patient, length of stay (LOS) in the ICU and inhospital, and in-hospital mortality. An extended duration of mechanical ventilation, length of stay in the ICU and inhospital, and the in-hospital mortality were considered as

\section{Flowchart screened patients}

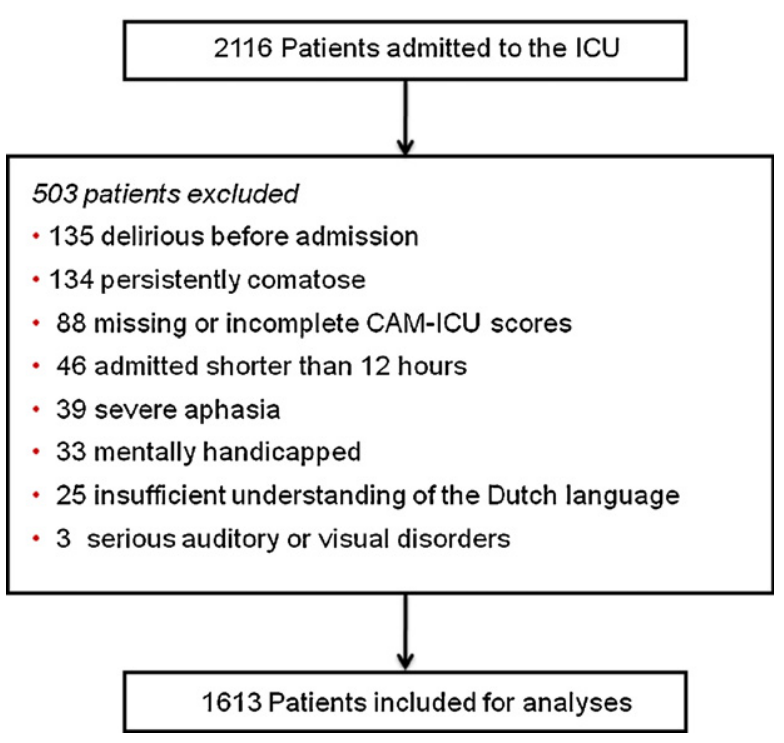

Fig. 1. Flowchart of patient inclusion. 
the most important short-term consequences since this harms the patients directly and the most.

Patients were divided in six admission categories: cardiac surgery, neurosurgical, surgical, neurological, medical and trauma. This classification was set by the attending physician and based on main reason for ICU admission.

\subsection{Variables}

Demographic variables of all included patients were collected such as age, gender, admission category, severity of illness expressed in Acute Physiology and Chronic Health Evaluation (APACHE-) II score. Furthermore, delirium outcome measures and short-term consequences were collected.

\subsection{Quality checks during data collection}

The performance of CAM-ICU screenings by the nurses was monitored to ensure the quality of data collection. Compliance was calculated as the percentage of assessments performed per day in relation to the total number of assessments that should have been performed. The mean compliance was $90.4 \%$. To determine the quality of the CAMICU performance, we measured the interrater reliability. For this, the CAM-ICU score assessed by the attending intensive care nurse was compared with the CAM-ICU score assessed by an expert psychiatry nurse within a time-window of $1 \mathrm{~h}$. One hundred-and-twenty interrater reliability measurements were performed at random resulting in a Cohen's kappa of 0.90 (95\%CI 0.82-0.98).

Furthermore, medical and nursing files of all patients were screened daily for signs of delirium (Inouye et al., 2005). When the files contained signs of delirium without a positive CAM-ICU screening or conversely, when files did not provide evidence of delirium while there was a positive CAM-ICU score, patients were additionally screened by a delirium expert according to the DSM-IV criteria (American Psychiatric Association, 1994) to rule out false negatives and positives. These signs were for instance lethargic or depressive behaviour or just picker or agitated behaviour which was not directly recognized or screened as delirium. In total 17 patients (1.1\%) were additionally screened by a delirium expert.

Finally, data-collection was randomly checked for accuracy in $15 \%$ of the patients by the first author.

\subsection{Statistical analyses}

Differences between delirium and non-delirium ICU patients and differences for the subtypes of delirium regarding the demographic characteristics and short-term consequences were tested non-parametrically using the Mann-Whitney $U$ test. Dichotomous variables were tested with the Chi-square test. To determine short-term consequences of delirium covariance analyses were performed to adjust for severity of illness. Since the distribution of the length of stay and duration of mechanical ventilation were skewed, data were log transformed resulting in normally distributed variables where after covariance analyses was performed. To take differences in duration of delirium into account, incidence rates of re-intubations, unplanned removal of catheters and the amount of removed catheters were calculated per 1000 delirium days. Differences in these incidence rates between delirium subtypes were tested using the Mann-Whitney $U$ test.

To determine the contribution of delirium to an extended duration of mechanical ventilation, length of stay in the ICU and in-hospital we used a multiple logistic regression analysis. The highest quartile of the duration of mechanical ventilation, length of stay in the ICU and in-hospital were used as cut-off value for the definition of extended duration of these variables. Important variables as delirium, age, severity of illness score, history of respiratory diseases, reintubation and sepsis were used as covariates.

Statistical significance was defined as a $P$-value $<0.05$. All data were analysed using SPSS version 16.01 (SPSS, Chicago, IL).

\section{Results}

In total 2116 consecutive patients were screened of which 503 were excluded (Fig. 1). The most common reasons for exclusion were sustained coma (26.8\%) and delirium before ICU admission (26.6\%).

\subsection{Delirium incidence and differences between delirious and non-delirious patients}

Out of the remaining 1613 patients, 411 (26\%) developed delirium during their ICU admission. When calculating the delirium incidence rate in the group of patients admitted to the ICU for two days or longer, the incidence rate increased to 53\%.

Demographic characteristics of the patients are shown in Table 1. Patients with delirium were significantly older, more likely to be admitted to the ICU for urgent reasons, more likely to be mechanically ventilated and their severity of illness score was significantly higher than that of ICU patients who did not develop delirium. The delirium incidence rates of the cardiac surgery and neurosurgical groups was significantly lower compared to the other groups (all $P<0.0001$ ), while the incidence rate in the neurology group was significantly higher than that in all other groups $(P<0.05)$.

\subsection{Delirium subtypes}

Regarding the delirium subtypes, the mixed subtype occurred most frequently, followed by the hypoactive delirium subtype (Table 2). The incidence of hyperactive delirium was significantly highest in the cardiac surgery group and the incidence of hypoactive delirium was significantly highest in the neurology and neurosurgical group, other differences between the delirium subtypes and admission categories are shown in Table 2.

\subsection{Duration of delirium, short-term consequences and mortality}

Overall the median delirium duration was 2 days [IQR $1-7$, range 1-74 days] and was longest in the mixed 
Table 1

Demographic characteristics of non-delirium and delirium patients.

\begin{tabular}{|c|c|c|c|c|c|}
\hline \multirow[b]{2}{*}{ Age (years) } & \multirow{2}{*}{$\begin{array}{l}\begin{array}{l}\text { Non-delirium } \\
(N=1202)\end{array} \\
61\end{array}$} & \multirow{2}{*}{$\begin{array}{c}\text { patients } \\
\pm 14\end{array}$} & \multicolumn{2}{|c|}{ Delirium patients $(N=411)$} & \multirow{2}{*}{$\begin{array}{c}P \text {-value } \\
<0.0001\end{array}$} \\
\hline & & & 64 & \pm 15 & \\
\hline Gender (M) & 792 & $(66 \%)$ & 235 & $(57 \%)$ & 0.001 \\
\hline Urgent admission $(N)$ & 526 & $(44 \%)$ & 326 & $(79 \%)$ & $<0.0001$ \\
\hline APACHE-II score (point) & 13 & \pm 5 & 18 & \pm 6 & $<0.0001$ \\
\hline Mechanically ventilated patients $(N)$ & 903 & $(75 \%)$ & 363 & $(88 \%)$ & $<0.0001$ \\
\hline \multicolumn{6}{|l|}{ Diagnosis group } \\
\hline Cardiac surgery $(N=793)$ & 698 & $(88 \%)$ & 95 & $(12 \%)^{*}$ & \\
\hline Surgical (217) & 160 & $(74 \%)$ & 57 & $(26 \%)$ & \\
\hline Medical $(N=360)$ & 205 & $(60 \%)$ & 155 & $(40 \%)$ & \\
\hline Trauma $(N=80)$ & 42 & $(53 \%)$ & 38 & $(47 \%)$ & \\
\hline Neurology $(N=89)$ & 30 & $(34 \%)$ & 59 & $(66 \%)^{* * *}$ & \\
\hline Neurosurgical $(N=74)$ & 67 & $(90 \%)$ & 7 & $(10 \%)^{*}$ & \\
\hline
\end{tabular}

APACHE-II score: Acute Physiology and Chronic Health Evaluation-II score. Data are expressed as mean \pm standard deviation or numbers of patients and percentages.

* Significantly lower incidence rate than the other admission types.

** Significantly highest delirium incidence rate.

Table 2

Subtypes of delirium in the six different admission categories.

\begin{tabular}{|c|c|c|c|c|c|c|}
\hline \multirow[b]{2}{*}{ Incidence rate } & \multicolumn{2}{|c|}{$\begin{array}{l}\text { Hyperactive } \\
\text { subtype }\end{array}$} & \multicolumn{2}{|c|}{$\begin{array}{l}\text { Hypoactive } \\
\text { subtype }\end{array}$} & \multicolumn{2}{|c|}{$\begin{array}{l}\text { Mixed } \\
\text { subtype }\end{array}$} \\
\hline & 44 & $(11 \%)$ & 148 & $(36 \%)$ & 219 & $(53 \%)$ \\
\hline $\begin{array}{l}\text { Cardiac surgery } \\
\qquad(N=95)\end{array}$ & 22 & $(23 \%)^{* *}$ & 38 & $(40 \%)$ & 35 & $(37 \%)^{* *}$ \\
\hline Surgical $(N=57)$ & 4 & $(7 \%)$ & 16 & $(28 \%)$ & 37 & $(65 \%)$ \\
\hline Medical $(N=155)$ & 12 & $(8 \%)$ & 52 & $(34 \%)$ & 91 & $(59 \%)$ \\
\hline Trauma $(N=38)$ & 4 & $(11 \%)$ & 9 & $(24 \%)$ & 25 & $(66 \%)$ \\
\hline Neurology $(N=59)$ & 2 & $(3 \%)^{*}$ & 29 & $(49 \%)^{*}$ & 28 & $(48 \%)$ \\
\hline Neurosurgical $(N=7)$ & 0 & $(0 \%)^{a}$ & 4 & $(57 \%)^{*}$ & 3 & $(43 \%)$ \\
\hline
\end{tabular}

subtype $(P<0.001)$. In 93 (23\%) of the delirious patients it was not possible to determine the delirium duration mostly for reasons of discharge to another hospital or because the patient died. Delirious patients more likely needed respiratory support for a longer time and their ICU length of stay was longer compared to non-delirious patients (Table 3 ). These differences were all significant, even after adjusting for severity of illness at the time of ICU admission using the APACHE-II score. Delirious patients were significantly more likely to remove their tubes and catheters than non-delirious patients. Removal of their gastro-intestinal feeding tube occurred most frequently
(51\%) in patients who suffered from delirium, followed by unplanned removal of the endotracheal tube (28\%). The incidence rate of unplanned removal of tubes and catheters was significantly highest in the hyperactive subgroup delirium. This subgroup also more frequently removed tubes and catheters than the hypoactive and mixed subtype of delirium when adjusted for delirium duration.

Patients with a mixed subtype suffered the most from the short-term consequences (Table 4). Patients with the hyperactive subtype suffered the least from the short-term consequences and the delirium duration in this subtype was the shortest $(P<0.0001)$.

Delirious patients were six times more likely to die as compared to non-delirious patients. This difference persisted following adjustment for severity of illness. Significantly more patients with a hypoactive and mixed subtype died compared to the hyperactive subtype.

The median duration of mechanical ventilation in the total group was 0.5 days [IQR $0.3-1.0]$. The median length of stay in the ICU and in-hospital was 1 day [IQR 1-3] and 9 days [IQR 5-19], respectively. The cut-off value of extended duration of mechanical ventilation was defined as a duration longer than 1 day and an extended length of stay in the ICU, and in-hospital was defined as a stay longer than 3 days and 19 days, respectively.

Adjusting for covariates delirium was after consistently and significantly associated to an extended duration of mechanical ventilation (odds ratio 7.0), length of stay in

Table 3

Differences between non-delirium and delirium patients on short-term consequences.

\begin{tabular}{|c|c|c|c|c|c|}
\hline \multirow[b]{2}{*}{ Days of mechanical ventilation } & \multirow{2}{*}{$\begin{array}{l}\begin{array}{l}\text { Non-delirium } \\
(N=1202)\end{array} \\
0.3\end{array}$} & \multirow{2}{*}{$\begin{array}{c}\text { patients } \\
{[0.2-0.6]}\end{array}$} & \multicolumn{2}{|c|}{ Delirium patients $(N=411)$} & \multirow{2}{*}{$\begin{array}{c}P \text {-value } \\
<0.0001\end{array}$} \\
\hline & & & 4.6 & {$[0.9-10.9]$} & \\
\hline Re-intubation $(N)$ & 6 & $(0.5)$ & 41 & $(10 \%)$ & $<0.0001$ \\
\hline Accidental removal of tubes, catheters $(N)$ & 7 & $(0.6)$ & 49 & $(11.9 \%)$ & $<0.0001$ \\
\hline Total number of removals ( $N$, frequency/patient) & 8 & $(1.1)$ & 95 & $(1.9)$ & 0.35 \\
\hline LOS-ICU (days) & 1 & {$[1-2]$} & 6 & {$[2-13]$} & $<0.0001$ \\
\hline LOS-Hospital (days) & 7 & {$[5-14]$} & 20 & {$[10-20]$} & $<0.0001$ \\
\hline Mortality rate $(\mathrm{N})$ & 40 & $(3 \%)$ & 73 & $(18 \%)$ & $<0.0001$ \\
\hline
\end{tabular}

LOS, length of stay. Data are expressed as medians [IQRs] or numbers of patients and percentages.

Adjusted for APACHE-II score using analysis of covariance. 
Table 4

Differences between subtypes of delirium in delirium incidence and duration and on short-term consequences.

\begin{tabular}{|c|c|c|c|c|c|c|c|c|c|}
\hline \multirow[b]{2}{*}{ Age (years, median [IQR]) } & \multicolumn{2}{|c|}{$\begin{array}{l}\text { Hyperactive } \\
\text { subtype }(N=44)\end{array}$} & \multirow{2}{*}{$\frac{P \text {-value }}{}{ }^{*}$} & \multicolumn{2}{|c|}{$\begin{array}{l}\text { Hypoactive } \\
\text { subtype }(N=148)\end{array}$} & \multirow{2}{*}{$\frac{P \text {-value }}{0.75^{\#}}$} & \multicolumn{2}{|c|}{$\begin{array}{l}\text { Mixed subtype } \\
(N=219)\end{array}$} & \multirow{2}{*}{$\frac{P \text {-value }}{0.13^{\dagger}}$} \\
\hline & 73 & {$[60-77]$} & & 67 & {$[57-75]$} & & 66 & {$[56-75]$} & \\
\hline APACHE-II score (point) & 16 & [13-19] & $0.10^{*}$ & 18 & [14-22] & $0.47^{\#}$ & 18 & [14-23] & $0.03^{\dagger}$ \\
\hline Delirium incidence rate & 44 & $(10.7 \%)$ & & 148 & $(36 \%)$ & & 219 & $(53.3 \%)$ & \\
\hline Delirium duration (days, median [IQR]) & 1 & {$[1-1]$} & $<0.001^{*}$ & 1 & {$[1-4]$} & $<0.001^{\#}$ & 4 & {$[2-13]$} & $<0.001^{\dagger}$ \\
\hline Mechanical ventilation (days, median [IQR] & 0.6 & {$[0.3-2.1]$} & $<0.001^{*}$ & 3 & {$[0.8-7.7]$} & $<0.001^{\#}$ & 6.9 & {$[1.7-13.8]$} & $<0.001^{\dagger}$ \\
\hline Re-intubation per 1000 delirium days & 68 & & $0.02^{*}$ & 22 & & $0.81^{\#}$ & 16 & & $0.01^{\dagger}$ \\
\hline $\begin{array}{l}\text { Incidence unplanned removal tubes, } \\
\text { catheters per } 1000 \text { delirium days }\end{array}$ & 227 & & $<0.001^{*}$ & 35 & & $0.78^{\#}$ & 40 & & $<0.001^{\dagger}$ \\
\hline $\begin{array}{l}\text { Frequency removal of tubes per } \\
1000 \text { delirium days }\end{array}$ & 386 & & $<0.001^{*}$ & 88 & & $0.97^{\#}$ & 86 & & $<0.001^{\dagger}$ \\
\hline LOS-ICU & 3 & {$[1-5]$} & $0.02^{*}$ & 5 & [2-9] & $0.001^{\#}$ & 9 & [3-17] & $<0.001^{\dagger}$ \\
\hline LOS in-hospital & 10 & [5-15] & $0.003^{*}$ & 17.5 & [8-32] & $0.003^{\#}$ & 24 & {$[13-48]$} & $<0.001^{\dagger}$ \\
\hline Deceased $(N)$ & 3 & $(6.8 \%)$ & $0.04^{*}$ & 28 & $(18.9 \%)$ & $0.53^{\#}$ & 42 & $(19.2 \%)$ & $0.03^{\dagger}$ \\
\hline
\end{tabular}

APACHE-II score: Acute Physiology and Chronic Health Evaluation-II score. LOS: length of stay.

* Difference between hyperactive and hypo active delirium subtype.

\# Difference between hypo active and mixed delirium subtype.

$\dagger$ Difference between hyperactive and mixed delirium subtype.

the ICU (odds ratio 8.6) and in-hospital (odds ratio 2.1), as well as with in-hospital mortality (odds ratio 2.1) (Table 5).

\section{Discussion}

In this study we observed that the overall delirium incidence is approximately a quarter of all ICU patients admitted for at least one day, and half of all ICU patients admitted for two days or longer. Important differences in incidence and subgroup distribution between patient categories exist. The incidence rate was the highest in the neurology group and the lowest in the cardiac- and neurosurgical group. The mixed delirium subtype occurred most frequently and also had the longest duration. The hyperactive subtype occurred the least and the duration was the shortest. Furthermore we found that delirium is associated with serious short-term health consequences, most prominently in patients with the mixed subtype. Additionally, delirium in ICU patients is significantly associated with an extended duration of mechanical ventilation, length of stay in the ICU and in-hospital, as well as with in-hospital mortality.

Our findings are of importance for clinical practice since this knowledge can contribute to taking preventive measures in patient categories with a high delirium incidence or to recognize patients who suffer the most from the consequences of delirium. To our knowledge the delirium incidence in patients admitted for neurological or neurosurgical reasons to the ICU has never been determined since these patients are mostly excluded in studies.

The high delirium incidence in ICU patients in this large prospective cohort study is in accordance with various studies (Balas et al., 2007; Dubois et al., 2001; Lin et al., 2004; Ouimet et al., 2007), but was lower than some authors reported (Ely et al., 2001a, 2007; Granberg Axell et al., 2002; Pisani et al., 2006). Differences between these delirium incidences rates are likely related to differences in admission categories and in- or exclusion of patients with a short ICU length of stay. Indeed, we show that exclusion of patients with an ICU LOS of $<2$ days and $\geq 2$ days importantly influences the incidence rate of delirium

Table 5

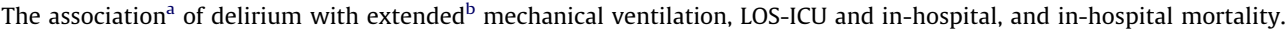

\begin{tabular}{|c|c|c|c|c|c|c|c|c|}
\hline \multirow[b]{3}{*}{ Delirium } & \multicolumn{2}{|c|}{ Extended mechanical ventilation } & \multirow{2}{*}{\multicolumn{2}{|c|}{$\begin{array}{l}\text { Extended LOS-ICU } \\
\text { OR }(95 \% \mathrm{CI})\end{array}$}} & \multirow{2}{*}{\multicolumn{2}{|c|}{$\begin{array}{l}\text { Extended LOS in-Hospital } \\
\text { OR }(95 \% \mathrm{CI})\end{array}$}} & \multirow{2}{*}{\multicolumn{2}{|c|}{$\begin{array}{l}\text { In-Hospital mortality } \\
\text { OR }(95 \% \mathrm{CI})\end{array}$}} \\
\hline & \multicolumn{2}{|l|}{ OR (95\%CI) } & & & & & & \\
\hline & 7.0 & $(4.7-10.5)$ & 8.6 & $(5.8-12.7)$ & 2.1 & $(1.5-3.0)$ & 2.1 & $(1.2-3.5)$ \\
\hline Age & 0.99 & $(0.97-1.01)$ & 0.99 & $(0.98-1.01)$ & 0.99 & $(0.99-1.01)$ & 1.03 & $(1.01-1.05)$ \\
\hline $\begin{array}{l}\text { APACHE-II } \\
\text { score }\end{array}$ & 1.07 & $(1.03-1.11)$ & 1.06 & $(1.03-1.1)$ & 1.08 & $(1.06-1.11)$ & 1.07 & $(1.03-1.11)$ \\
\hline Sepsis & 2.6 & $(1.2-5.6)$ & 2.6 & $(1.3-5.3)$ & 1.3 & $(0.8-2.2)$ & 2.9 & $(1.6-5.1)$ \\
\hline Use of sedatives & 2.9 & $(1.8-4.6)$ & 1.3 & $(0.8-2.1)$ & 1.0 & $(0.7-1.5)$ & 0.5 & $(0.3-0.99)$ \\
\hline $\begin{array}{l}\text { Non-sustained } \\
\text { coma }\end{array}$ & 5.6 & $(3.5-9.0)$ & 3.4 & $(2.1-5.7)$ & 1.3 & $(0.9-2.0)$ & 1.6 & $(0.8-3.2)$ \\
\hline $\begin{array}{l}\text { Respiratory } \\
\text { diseases }\end{array}$ & 1.9 & $(1.3-2.9)$ & 2.3 & $(1.6-3.4)$ & 1.8 & $(1.4-2.5)$ & 2.4 & $(1.5-3.9)$ \\
\hline Re-intubation & 30.1 & $(7.6-119.4)$ & 18.6 & $(5.4-63.5)$ & 5.6 & $(2.5-12.7)$ & 1.6 & $0.7-3.6)$ \\
\hline
\end{tabular}

LOS, length of stay; OR, odds ratio with 95\% confidence interval; APACHE-II score, Acute Physiology and Chronic Health Evaluation-II score.

a Using multiple logistic regression analysis.

b Using the highest quartile of duration was used as cut-off value. 
and that incidence varies greatly between diagnostic groups. Categorising the delirium incidence rate between ICU admission diagnosis group shows that there are notable differences that can be useful for others when interpreting measured delirium incidence rates.

Our results concerning the short-term consequences of delirium confirm previous work showing that delirious patients are mechanically ventilated for a significantly longer time (Shehabi et al., 2010), have a longer ICU and inhospital length of stay (Ely et al., 2001a) and are more likely to die (Ely et al., 2004; Lin et al., 2004). However, none of these studies reported differences between the subtypes of delirium. Overall, delirious patients had significantly more short-term health problems than nondelirious patients and these problems were most profound in the mixed subtype, which also had the longest duration.

Regarding these subtypes of delirium, the hyperactive subtype occurred the most in cardiac surgery patients, this subtype had the shortest duration and the fewest shortterm consequences compared with the hypoactive and mixed subtype. However in practice, nurses and physicians experience the most difficulties with patients with this easily recognizable delirium subtype. These patients are often agitated and consequently pull out their lines or endotracheal tube. Adjusted incidence rates of re-intubation and unplanned removal of catheters and tubes confirm these experiences of caregivers.

We found several significant differences for delirium subtypes and admission categories of which difference between the incidence of hyperactive delirium in the cardiac surgery and neurosurgical group is remarkable. There are only a few studies which reported incidence rates of delirium subtypes but these were only in medical (Peterson et al., 2006) or surgical and trauma patients (Pandharipande et al., 2007). Except for the higher incidence rate in the hyperactive group in our study, mainly caused by the high incidence rate in cardiac surgery patients, the numbers of the hypoactive and mixed subtype of delirium are rather comparable with these other reports.

Some limitations of this study need to be considered. Firstly, we did not use the 'gold standard' to diagnose delirium, but the CAM-ICU, which is a delirium screening tool. This screening tool is however, the most frequently used tool worldwide, and has the highest sensitivity and specificity and a high inter-rater reliability (Devlin et al., 2007; van den Boogaard et al., 2010). Moreover, to secure that no false negative or positive delirium assessments were used for the calculations in this study we also checked patients' files and if necessary a delirium expert additionally screened these patients. Therefore, we believe our assessment is valid and our incidence rate is reliable. However, one may argue that our overall incidence rate is low compared to other studies on delirium in the ICU, and hence may not be reliable. We attribute this low incidence to the fact that we included a large number of cardiac surgical patients, of which most have an ICU stay of one day and a low incidence of delirium (Kazmierski et al., 2010; van der Mast and Roest, 1996). When we excluded the patients with an ICU stay of only one day our incidence rate became comparable to that of other studies. Secondly, we excluded more than $20 \%$ of our screened patients. For this study we used similar exclusion criteria as others did when using the CAM-ICU (Ely et al., 2001a; Spronk et al., 2009). The most frequent reason for exclusion was 'delirious before ICU admission' which must be considered as a normal exclusion criteria when determining the incidence rate. Sustained coma was the second most frequent reason which occurred the most in neurological patients. This patient category is mostly excluded in other studies. Despite we included also patients admitted to the ICU for a neurological disease, we excluded a similar amount of patients when compared with other studies which ranges up to $43 \%$ (Dubois et al., 2001; Ely et al., 2004; Ouimet et al., 2007; Van Rompaey et al., 2009).

Thirdly, in this prospective cohort study we determined that delirium is associated with several short-term consequences which does not necessarily indicate there is a causal relationship between delirium and the outcome parameter. Our study design is too limited to draw these strong conclusions. Despite this limitation it is important to recognize that delirium is a serious disorder with serious short-term consequences and our results corroborates findings of other smaller studies (Ely et al., 2001a, 2004; Pisani et al., 2009).

Lastly, in our study a notable number of patients died or were discharged to other hospitals before the end of the delirium episode and like others (van Eijk et al., 2010) we did not include the residual duration of their delirium period. One may argue that this resulted in an underestimation of the delirium duration and unplanned removal of tubes and catheters. Although this could have influenced the delirium duration, this calculation method will not influence the incidence of unplanned removal of tubes and catheters as all these patients were already discharged from the ICU to the ward and therefore had less indwelling tubes and catheters.

\section{Conclusion}

Over a quarter of our ICU population with a length of stay $>1$ day and half of the ICU patients with a length of stay of $\geq 2$ days developed delirium during their ICU stay. There is an important difference between admission categories concerning the delirium incidence rates and the occurrence of subtypes of delirium. Patients who developed delirium were significantly more likely to suffer from short-term health problems and had a six times higher chance of dying compared to ICU patients who did not develop delirium, independently of their severity of illness. The problems were most pronounced in patients with a mixed subtype of delirium.

In summary, the high delirium incidence rate and serious short term health related problems for patients must be sufficient to convince health care professionals to screen patients for delirium and should encourage nurses to take preventive measures such as cognitive stimulation (Inouye et al., 1999), music therapy (McCaffrey and Locsin, 2006), prophylactic haloperidol (Kalisvaart et al., 2005; Kaneko et al., 1999) or early mobilization (Schweickert et al., 2009) of which the latter is the only measure which was examined in ICU patients. 
Conflict of interest: All authors declare that they have no financial/commercial conflicts of interest.

Authors' contributions: MvdB carried out the study, the statistics and drafted the manuscript. LS and PP were involved in the design, supervised the study and helped to draft the manuscript. JvdH and TvA supervised the study and corrected the manuscript. All authors read and approved the final manuscript.

Grants: None.

Ethical approval: The regional Medical Ethical Committee approved the study and waived the need for informed consent, since no additional interventions were carried out and data collection was not burdensome to patients.

\section{Acknowledgements}

The authors would like to thank Gabriel Roodbol, delirium expert nurse psychiatry, who carried out all the inter-rater reliability measurements during the study. Many thanks to Henk Westerbaan, Maaike Fenten and Wendy Groetelaers-Kusters, for collecting data during the absence of the first author and processing the data in SPSS. We also would like to thank Sjef van der Velde for his support in gathering the electronic database information. Last, we would like to thank Gareth Parsons (University of Glamorgan, Faculty of Health, Sport and Science, UK) for his English grammar and spelling support.

\section{References}

Aldemir, M., Ozen, S., Kara, I.H., Sir, A., Bac, B., 2001. Predisposing factors for delirium in the surgical intensive care unit. Crit. Care 5 (5), 265270.

American Psychiatric Association, 1994. Diagnostic and Statistical Manual of Mental Disorders (DSM-IV). Washington, DC.

Balas, M.C., Deutschman, C.S., Sullivan-Marx, E.M., Strumpf, N.E., Alston, R.P., Richmond, T.S., 2007. Delirium in older patients in surgical intensive care units. J. Nurs. Sch. 39 (2), 147-154.

Devlin, J.W., Fong, J.J., Fraser, G.L., Riker, R.R., 2007. Delirium assessment in the critically ill. Intensive Care Med. 33 (6), 929-940.

Dubois, M.J., Bergeron, N., Dumont, M., Dial, S., Skrobik, Y., 2001. Delirium in an intensive care unit: a study of risk factors. Intensive Care Med. 27 (8), 1297-1304.

Ely, E.W., Gautam, S., Margolin, R., Francis, J., May, L., Speroff, T., Truman, B., Dittus, R., Bernard, R., Inouye, S.K., 2001a. The impact of delirium in the intensive care unit on hospital length of stay. Intensive Care Med. 27 (12), 1892-1900.

Ely, E.W., Girard, T.D., Shintani, A.K., Jackson, J.C., Gordon, S.M., Thomason, J.W., Pun, B.T., Canonico, A.E., Light, R.W., Pandharipande, P., Laskowitz, D.T., 2007. Apolipoprotein E4 polymorphism as a genetic predisposition to delirium in critically ill patients. Crit. Care Med. 35 (1), $112-117$.

Ely, E.W., Inouye, S.K., Bernard, G.R., Gordon, S., Francis, J., May, L., Truman, B., Speroff, T., Gautam, S., Margolin, R., Hart, R.P., Dittus, R., 2001 b. Delirium in mechanically ventilated patients: validity and reliability of the confusion assessment method for the intensive care unit (CAMICU). JAMA 286 (21), 2703-2710.

Ely, E.W., Margolin, R., Francis, J., May, L., Truman, B., Dittus, R., Speroff, T. Gautam, S., Bernard, G.R., Inouye, S.K., 2001c. Evaluation of delirium in critically ill patients: validation of the Confusion Assessment Method for the Intensive Care Unit (CAM-ICU). Crit. Care Med. 29 (7), 1370-1379.

Ely, E.W., Shintani, A., Truman, B., Speroff, T., Gordon, S.M., Harrell Jr., F.E., Inouye, S.K., Bernard, G.R., Dittus, R., 2004. Delirium as a predictor of mortality in mechanically ventilated patients in the intensive care unit. JAMA 292 (2), 168-169.

Ely, E.W., Truman, B., Shintani, A., Thomason, J.W., Wheeler, A.P., Gordon, S., Francis, J., Speroff, T., Gautam, S., Margolin, R., Sessler, C.N., Dittus, R.S., Bernard, G.R., 2003. Monitoring sedation status over time in ICU patients: reliability and validity of the Richmond Agitation-Sedation Scale (RASS). JAMA 289 (22), 2983-2991.

Girard, T.D., Jackson, J.C., Pandharipande, P.P., Pun, B.T., Thompson, J.L., Shintani, A.K., Gordon, S.M., Canonico, A.E., Dittus, R.S., Bernard, G.R. Ely, E.W., 2010. Delirium as a predictor of long-term cognitive impairment in survivors of critical illness. Crit. Care Med. 38 (7), 15131520.

Granberg Axell, A.I., Malmros, C.W., Bergbom, I.L., Lundberg, D.B., 2002. Intensive care unit syndrome/delirium is associated with anemia, drug therapy and duration of ventilation treatment. Acta Anaesthesiol. Scand. 46 (6), 726-731.

Inouye, S.K., Bogardus Jr., S.T., Charpentier, P.A., Leo-Summers, L., Acampora, D., Holford, T.R., Cooney Jr., L.M., 1999. A multicomponent intervention to prevent delirium in hospitalized older patients. $\mathrm{N}$. Engl. J. Med. 340 (9), 669-676.

Inouye, S.K., Leo-Summers, L., Zhang, Y., Bogardus Jr., S.T., Leslie, D.L., Agostini, J.V., 2005. A chart-based method for identification of delirium: validation compared with interviewer ratings using the confusion assessment method. J. Am. Geriatr. Soc. 53 (2), 312-318.

Kalisvaart, K.J., de Jonghe, J.F., Bogaards, M.J., Vreeswijk, R., Egberts, T.C., Burger, B.J., Eikelenboom, P., van Gool, W.A., 2005. Haloperidol prophylaxis for elderly hip-surgery patients at risk for delirium: a randomized placebo-controlled study. J. Am. Geriatr. Soc. 53 (10), 1658-1666.

Kaneko, T., Cai, J., Ishikura, T., Kobayashi, M., Naka, T., Kaibara, N., 1999. Prophylactic consecutive administration of haloperidol can reduce the occurrence of postoperative delirium in gastrointestinal surgery. Yonago Acta Med. 42 (3), 179-184.

Kazmierski, J., Kowman, M., Banach, M., Fendler, W., Okonski, P., Banys, A., Jaszewski, R., Rysz, J., Mikhailidis, D.P., Sobow, T., Kloszewska, I., 2010. Incidence and predictors of delirium after cardiac surgery: results from the IPDACS study. J. Psychosom. Res. 69 (2), 179-185.

Knaus, W.A., Draper, E.A., Wagner, D.P., Zimmerman, J.E., 1985. APACHE II: a severity of disease classification system. Crit. Care Med. 13 (10), 818-829.

Lin, S.M., Liu, C.Y., Wang, C.H., Lin, H.C., Huang, C.D., Huang, P.Y., Fang, Y.F. Shieh, M.H., Kuo, H.P., 2004. The impact of delirium on the survival of mechanically ventilated patients. Crit. Care Med. 32 (11), 2254-2259.

McCaffrey, R., Locsin, R., 2006. The effect of music on pain and acute confusion in older adults undergoing hip and knee surgery. Holist. Nurs. Pract. 20 (5), 218-224.

McNicoll, L., Pisani, M.A., Zhang, Y., Ely, E.W., Siegel, M.D., Inouye, S.K. 2003. Delirium in the intensive care unit: occurrence and clinical course in older patients. J. Am. Geriatr. Soc. 51 (5), 591-598.

Meagher, D.J., O'Hanlon, D., O’Mahony, E., Casey, P.R., Trzepacz, P.T., 2000. Relationship between symptoms and motoric subtype of delirium. J. Neuropsychiatry Clin. Neurosci. 12 (1), 51-56.

Meagher, D.J., Trzepacz, P.T., 2000. Motoric subtypes of delirium. Semin. Clin. Neuropsychiatry 5 (2), 75-85.

Ouimet, S., Kavanagh, B.P., Gottfried, S.B., Skrobik, Y., 2007. Incidence, risk factors and consequences of ICU delirium. Intensive Care Med. 33 (1), $66-73$.

Pandharipande, P., Cotton, B.A., Shintani, A., Thompson, J., Costabile, S., Truman, P.B., Dittus, R., Ely, E.W., 2007. Motoric subtypes of delirium in mechanically ventilated surgical and trauma intensive care unit patients. Intensive Care Med. 33 (10), 1726-1731.

Peterson, J.F., Pun, B.T., Dittus, R.S., Thomason, J.W., Jackson, J.C., Shintani, A.K., Ely, E.W., 2006. Delirium and its motoric subtypes: a study of 614 critically ill patients. J. Am. Geriatr. Soc. 54 (3), 479-484.

Pisani, M.A., Araujo, K.L., Van Ness, P.H., Zhang, Y., Ely, E.W., Inouye, S.K., 2006. A research algorithm to improve detection of delirium in the intensive care unit. Crit. Care 10 (4), R121.

Pisani, M.A., Kong, S.Y., Kasl, S.V., Murphy, T.E., Araujo, K.L., Van Ness, P.H., 2009. Days of delirium are associated with 1-year mortality in an older intensive care unit population. Am. J. Respir. Crit. Care Med. 180 (11), 1092-1097.

Pretto, M., Spirig, R., Milisen, K., Degeest, S., Regazzoni, P., Hasemann, W., 2009. Effects of an interdisciplinary nurse-led Delirium Prevention and Management Program (DPMP) on nursing workload: a pilot study. Int. J. Nurs. Stud. 46 (6), 804-812.

Schuurmans, M.J., Shortridge-Baggett, L.M., Duursma, S.A., 2003. The Delirium Observation Screening Scale: a screening instrument for delirium. Res. Theory Nurs. Pract. 17 (1), 31-50.

Schweickert, W.D., Pohlman, M.C., Pohlman, A.S., Nigos, C., Pawlik, A.J., Esbrook, C.L., Spears, L., Miller, M., Franczyk, M., Deprizio, D., Schmidt, G.A., Bowman, A., Barr, R., McCallister, K.E., Hall, J.B., Kress, J.P., 2009. Early physical and occupational therapy in mechanically ventilated, critically ill patients: a randomised controlled trial. Lancet 373 (9678), 1874-1882. 
Shehabi, Y., Riker, R.R., Bokesch, P.M., Wisemandle, W., Shintani, A., Ely, E.W., 2010. Delirium duration and mortality in lightly sedated, mechanically ventilated intensive care patients. Crit. Care Med. 38 (12), 2311-2318.

Spronk, P.E., Riekerk, B., Hofhuis, J., Rommes, J.H., 2009. Occurrence of delirium is severely underestimated in the ICU during daily care. Intensive Care Med. 35 (7), 1276-1280.

van den Boogaard, M., Pickkers, P., Schoonhoven, L., 2010. Assessment of delirium in ICU patients: a literature review. Neth. J. Crit. Care 14 (1), $10-15$.

van den Boogaard, M., Pickkers, P., van der Hoeven, H., Roodbol, G., van Achterberg, T., Schoonhoven, L., 2009. Implementation of a delirium assessment tool in the ICU can influence haloperidol use. Crit. Care 13 (4), R131.

van der Mast, R.C., Roest, F.H., 1996. Delirium after cardiac surgery: a critical review. J. Psychosom. Res. 41 (1), 13-30. van Eijk, M.M., Roes, K.C., Honing, M.L., Kuiper, M.A., Karakus, A., van der, J.M., Spronk, P.E., van Gool, W.A., van der Mast, R.C., Kesecioglu, J., Slooter, A.J., 2010. Effect of rivastigmine as an adjunct to usual care with haloperidol on duration of delirium and mortality in critically ill patients: a multicentre, double-blind, placebo-controlled randomised trial. Lancet 376 (9755), 1829-1837.

Van Rompaey, B., Elseviers, M.M., Schuurmans, M.J., Shortridge-Baggett, L.M., Truijen, S., Bossaert, L., 2009. Risk factors for delirium in intensive care patients: a prospective cohort study. Crit. Care 13 (3), R77.

Van Rompaey, B., Schuurmans, M.J., Shortridge-Baggett, L.M., Truijen, S., Bossaert, L., 2008. Risk factors for intensive care delirium: a systematic review. Intensive Crit. Care Nurs. 24 (2), 98-107.

Vreeswijk, R., Toornvliet, A., Honing, M., Bakker, K., de Man, T., Daas, G., Spronk, P., de Jonghe, J.F., Kalisvaart, K.J., 2009. Validation of the Dutch version of the Confusion Assessment Method (CAM-ICU) for delirium screening in the intensive care unit. Neth. J. Crit. Care 13 (2), 73-78. 